\title{
VIBRATION ARTHROGRAPHY AS A DIAGNOSTIC AID IN DISEASES OF THE KNEE
}

\author{
A PRELIMINARY REPORT
}

GERALD F. MCCOY, JOHN D. MCCREA, DAVID E. BEVERLAND, W. GEORGE KERNOHAN, RAYMOND A. B. MOLLAN

\begin{abstract}
The detection and recording of vibration emission from human joints, a technique which we have termed "vibration arthrography", is a sensitive, non-invasive method for the objective study of the locomotor system. Using vibration sensors attached to bony prominences around the knee, we studied the joints of both normal and symptomatic subjects. Normal subjects produced three signal types - physiological patellofemoral crepitus, patellar clicks, and the lateral band signal. In symptomatic subjects we indentified and categorised many signal types and related them to pathology. Lesions of the menisci produced distinctive signals, and it was possible not only to lateralise the tear, but in many cases to determine the type of meniscal injury present. Vibration arthrography promises to be a useful tool in the non-invasive diagnosis of knee disorders.
\end{abstract}

The knee is the most commonly injured joint in the body and it has been estimated that knee injuries account for $65 \%$ to $75 \%$ of orthopaedic consultations (Jackson and Abe 1972). Accurate diagnosis has, until recently, required the expensive and invasive techniques of arthrography and arthroscopy. We report the development of a non-invasive diagnostic aid, with an accuracy rate approaching that of arthrography.

In 1885 , Heuter reported the first study involving the evaluation of sounds from the locomotor system when he described the localisation of loose bodies within the knee using a stethoscope. Since that time, there have been many studies evaluating joint sounds. The earlier studies involved stethoscopic examination (Blodgett 1902: Bircher 1913; Walters 1929), but subsequently, to reduce subjectivity, microphones have been increasingly used (Erb 1933; Fischer and Johnson 1960; Danis Szabó and Török 1972). In 1974, Oehl and his colleagues used the term "phonoarthrography" to describe all microphone-based investigations of joint sounds. Despite the increasing sophistication of the computer recording and analysis techniques pioneered by $\mathrm{Chu}$ et al. (1976a,b, 1978), microphone-based studies continued to be limited by the shortcomings of all acoustic systems:

J. D. McCrea, MD, MRCP(UK), Senior Registrar in Rheumatology Musgrave Park Hospital, Belfast BT9 $7 \mathrm{JB}$, Northern Ireland.

G. F. McCoy, MD, FRCS, Senior Orthopaedic Registrar D. E. Beverland, MD, FRCS, Former Research Assistant W. G. Kernohan, BSc, PhD, Lecturer in Bio-engineering R. A. B. Mollan, MD, FRCS. Professor of Orthopaedic Surgery Department of Orthopaedic Surgery, The Queen's University of Belfast, Musgrave Park Hospital, Belfast BT9 7JB, Northern Ireland.

Requests for reprints should be sent to Mr G. F. McCoy. (C) 1987 British Editorial Society of Bone and Joint Surgery $0301-620 \mathrm{X} / 87 / 2066 \$ 2.00$ chiefly the poor response to low-frequency signals and distortion caused by background noise.

The use of a vibration-sensitive sensor (or accelerometer) to record joint signals overcomes the problems inherent in acoustic systems. Mang, Birk and Blümel (1980) published the first study using this equipment but did not discuss their reasons for choosing accelerometers as sensors, nor did they appear to realise the significance of their choice. It was left to Mollan, McCullagh and Wilson (1982) and more recently to McCrea et al. (1985) to describe the considerable advantages of the use of vibration sensors to detect joint signals. Further work is now appearing in the literature (Cowie et al. 1984; Wallace, Mollan and Kernohan 1985). This paper reports our early experience of vibration detection in the diagnosis of knee injury and discusses the clinical possibilities of this technique. We propose that this technique be known as "vibration arthrography".

\section{MATERIALS AND METHODS}

The accelerometers which are applied to the skin are sensitive to vibration at their point of application, and therefore the problem of background noise, which affects microphone-based systems, is minimised. Their small size and the fact that they can be securely fixed avoids skin friction noise. Cable noise is removed by the use of pre-amplification.

We chose BBN Series 501 accelerometers of mass $1.8 \mathrm{~g}$, with integral pre-amplifiers, as the most suitable sensors, being sufficiently small $(1.3 \times 0.7 \mathrm{~cm})$ and light for our purpose. The sensors were positioned one each over the medial and lateral femoral condyles, approximately $1 \mathrm{~cm}$ above the joint line, and one over the patella. 


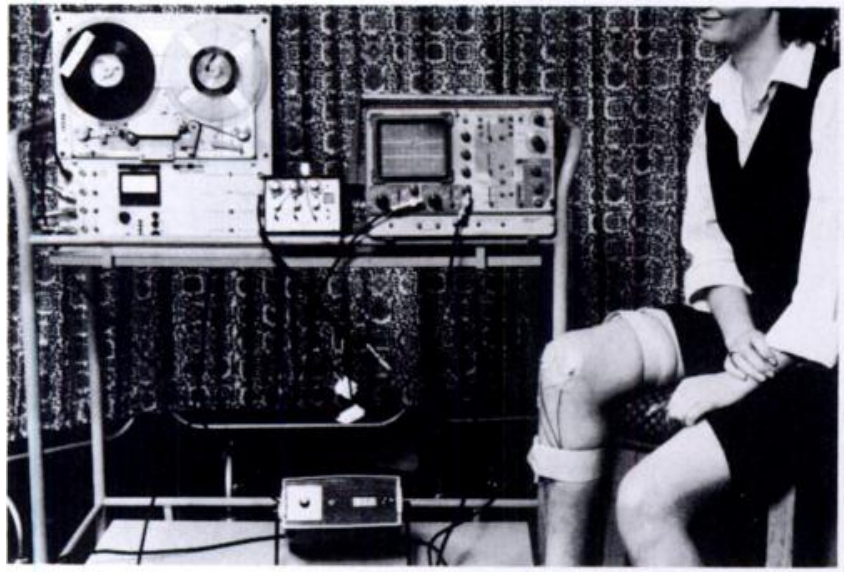

Fig. 1

Subject attached to the recording apparatus.

Their output was recorded on a four-channel FM tape recorder, the fourth channel being used to record the signal from an electronic goniometer attached to the lateral aspect of the limb. The signals were monitored using a digital oscilloscope (Gould Type OSO400). The recording apparatus is seen attached to a subject in Figure 1.

For examination purposes, a series of active limb cycles and passive stress cycles were used. A cycle was defined as one complete movement from $90^{\circ}$ of flexion to full extension and back to $90^{\circ}$ of flexion. With asymptomatic subjects, both slow $(12,20$ and 40 seconds per cycle) and fast active cycles (2, 4 and 6 seconds per cycle) were recorded, each optimally displaying a different normal knee signal. With symptomatic knees, only fast active cycles and passive stress cycles (valgus, varus and McMurray's rotational test) were used. These cycle speeds had previously been demonstrated to give the best display of pathological knee signals. All the symptomatic subjects had been admitted for arthros- copy, having previously been seen as outpatients; the decision to proceed to arthroscopy was made on clinical grounds alone. The arthroscopic examinations were performed in each case by the same experienced arthroscopist and thus it was possible to correlate signals with observed pathology directly.

For analysis purposes, the tapes were played initially at normal speed, and subsequently, after identifying sections of interest, at one-eighth speed (via an oscilloscope) into a frequency analyser. This automatically analysed the input signal in terms of its frequency content by performing a Fast Fourier Transform (FFT) on the input data. Then, to permit computation and digital storage of additional parameters, the frequency analyser was linked to a microcomputer (Kernohan and Mollan 1982). The results of this "dual microprocessor" analysis were given in terms of the size of the shock (acceleration range), power content (root mean square or RMS), peak frequency and decibel (dB) level. It was then possible to analyse the output from all three sensors and to determine the side on which the maximal signal occurred.

Using this method, we recorded the vibration output from 250 normal and 247 symptomatic subjects. The normal subjects had no past history of knee disorders, and comprised hospital workers, secondary school students and industrial workers. The symptomatic subjects had all been admitted for arthroscopy. A proportion of those subjects who underwent meniscal resection were resubmitted to vibration arthrography three months to one year after surgery.

\section{RESULTS}

Normal knees Within the normal group of subjects, three signal types were commonly observed.

Physiological patellofemoral crepitus (PPC). With slow cycle speeds a quasi-periodic signal (Fig. 2) was recorded over the patella in $99 \%$ of subjects. The phenomenon of

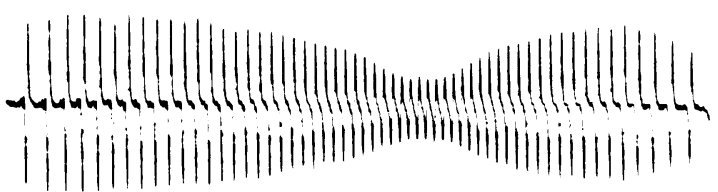

Fig. 2

Normal knees. Figure 2 - Vibration tracing of physiological patellofemoral crepitus. Figure 3 - The patellar click as it appears on three channels (from the medial and lateral femoral condyles and from the patella). Note that the maximal displacement occurs over the patella. Figure 4 The lateral band phenomenon is characterised by a large displacement on the lateral channel with little or no transmission to the other two channels.

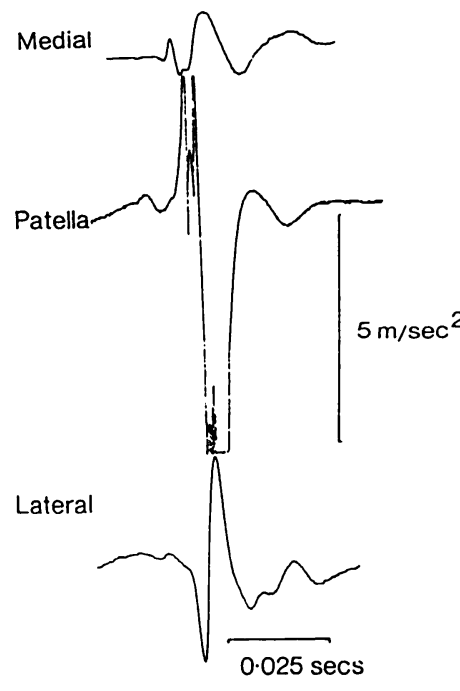

Fig. 3
Medial

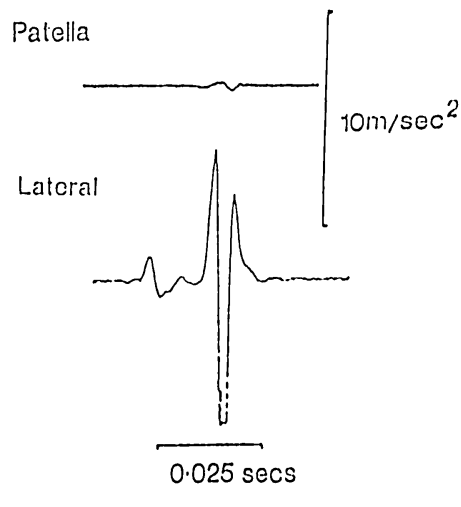

Fig. 4 
PPC was palpable over the patella as a fine creaking sensation during slow flexion and extension of the knee. This signal was absent during fast cycles, and was generally not seen at speeds faster than 20 seconds per cycle; it was augmented by joint loading and abolished by patellectomy; it was diminshed but not abolished by inducing an effusion. A diminution in both incidence and amplitude of this vibration occurred with progressive cartilage deterioration.

Patellar click. With the faster cycle speeds in normal subjects, an isolated (transient) signal was commonly observed, again maximal over the patella (Fig. 3). The incidence of the patellar click was directly related to cycle speed, being increased in both amplitude and occurrence in faster cycles. The click was also a palpable phenomenon and was most obvious during the extension phase of the cycle. The energies recorded from patellar clicks ranged from 1.5 to $>30 \mathrm{~m} / \mathrm{s}^{2}$, and the peak frequencies were in the range 40 to $140 \mathrm{~Hz}$. Occasionally, a click was also observed with the knee in extreme flexion.

Lateral band phenomenon. A third signal, present in $22 \%$ of normal subjects, was demonstrated to originate from the lateral side of the joint. It was found to be present more frequently in males $(\mathrm{M}=28 \%, \mathrm{~F}=11 \%)$ and was often a powerful signal with an acceleration range of over $12 \mathrm{~m} / \mathrm{s}^{2}$. However, no displacement was detected by the other sensors (Fig. 4). The signal was seen almost exclusively in the extension phase of the cycle, the angle of occurrence lying between $55^{\circ}$ and $19^{\circ}$. This corresponded approximately to the angle at which the iliotibial tract crossed the lateral femoral condyle and it was often palpable as a distinct click. This vibration tracing seemed to result from impingement of the ilio-tibial band against the lateral femoral condyle during active excursion of the knee.

Symptomatic knees Of more relevance for diagnostic purposes were the vibration arthrography tracings obtained from symptomatic knees, especially those relating to meniscal injuries.

Meniscal signals. Of the 247 subjects who underwent arthroscopy, 174 were demonstrated to have meniscal pathology; 150 of these $(86 \%)$ produced meniscal signals. There were 55 patients with posterior horn tears, while 43 had bucket-handle meniscal tears. In 27 cases miscellaneous tears (cleavage, radial, etc) were identified. There were 25 cases in which the meniscus was demonstrated to be unduly mobile, thereby imparting a signal. False negatives were seen in 10 cases where the knee was mechanically locked, and six cases where significant effusion was present.

The meniscal signal was characteristic, was produced by no other intra-articular lesion and was always largest on the affected side. In this series, signals were observed in 85 cases of medial meniscal injury, and 65 cases where the lateral meniscus was affected. With lateral meniscal signals, a very large displacement was seen on the lateral channel, with much smaller signals

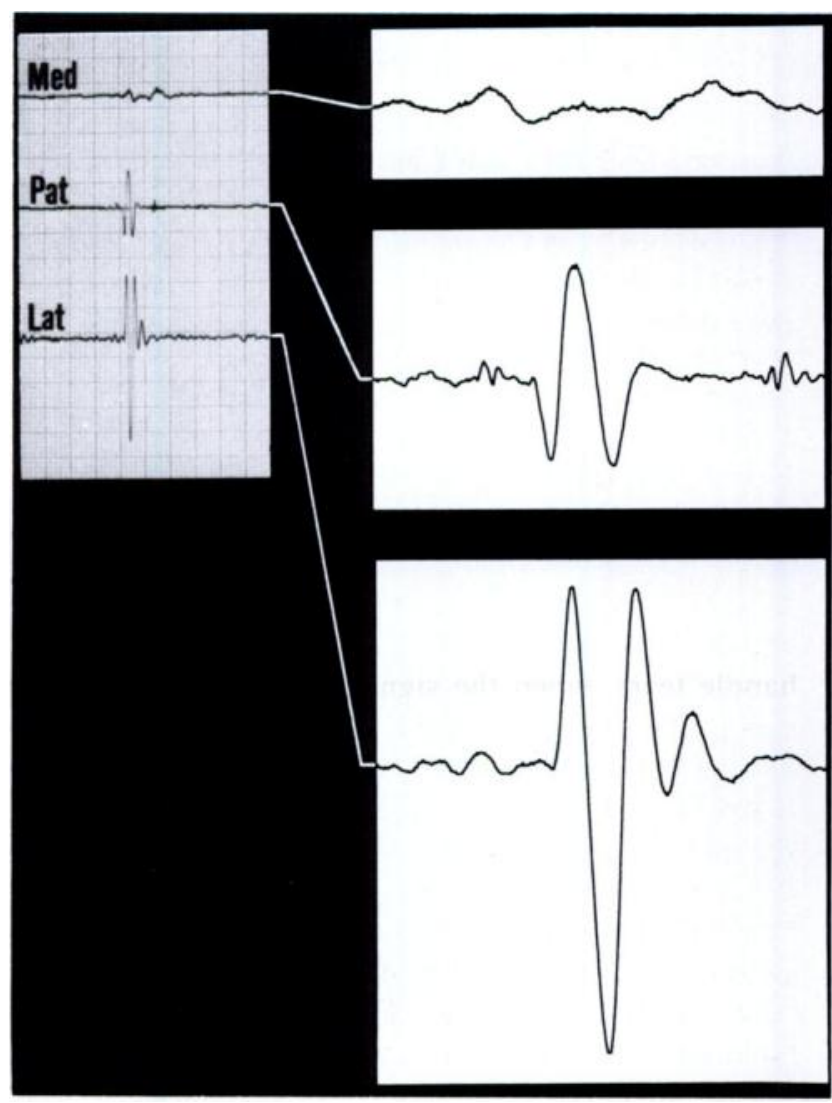

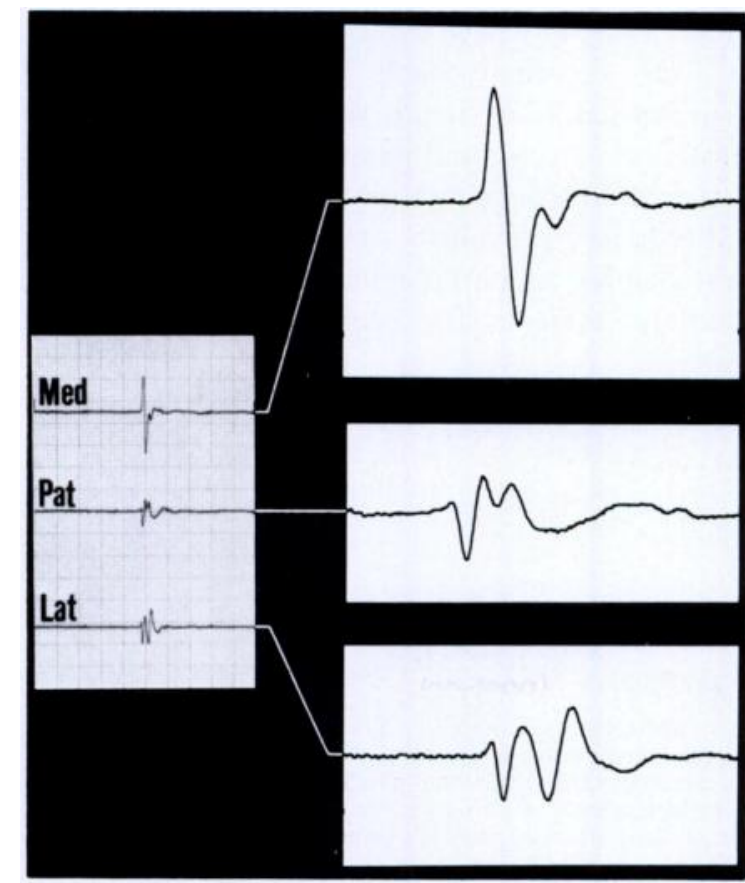

Fig. 6

Fig. 5

Typical tracings produced by a tear of the lateral meniscus (Fig. 5) and the medial meniscus (Fig. 6). A displacement is noted to occur simultaneously on all three channels, with the maximum on the affected side. 
over the patella and medial channels (Fig. 5). The signal was not an isolated phenomenon, but occurred repeatedly at approximately the same angle in the cycle. With medial meniscal damage, the largest signal occurred on the medial side, with smaller signals over the lateral side and over the patella (Fig. 6). Meniscal signals were generally in the range 1 to $30 \mathrm{~m} / \mathrm{s}^{2}$, with a power content (RMS) 0.5 to 6.0. The peak frequency varied from 25 to $320 \mathrm{~Hz}$ with a median of $108 \mathrm{~Hz}$, i.e. they were lowfrequency signals, often inaudible.

Surgery was demonstrated to have a profound effect on signal strength. Figure 7 shows the tracings before and after operation in a patient with a tear of the lateral meniscus. The acceleration range on the lateral side was reduced from $>15 \mathrm{~m} / \mathrm{s}^{2}$ to $1.7 \mathrm{~m} / \mathrm{s}^{2}$, and there was almost complete resolution of symptoms. The medial signal in both tracings had an identical waveform, although the amplitude was reduced in the postoperative tracing.

Plica signal. Other conditions of the knee were demonstrated to give characteristic waveforms. The synovial plica produces symptoms when it impinges on the femoral condyles during flexion and extension (Glasgow et al. 1981). During knee movements therefore, the plica
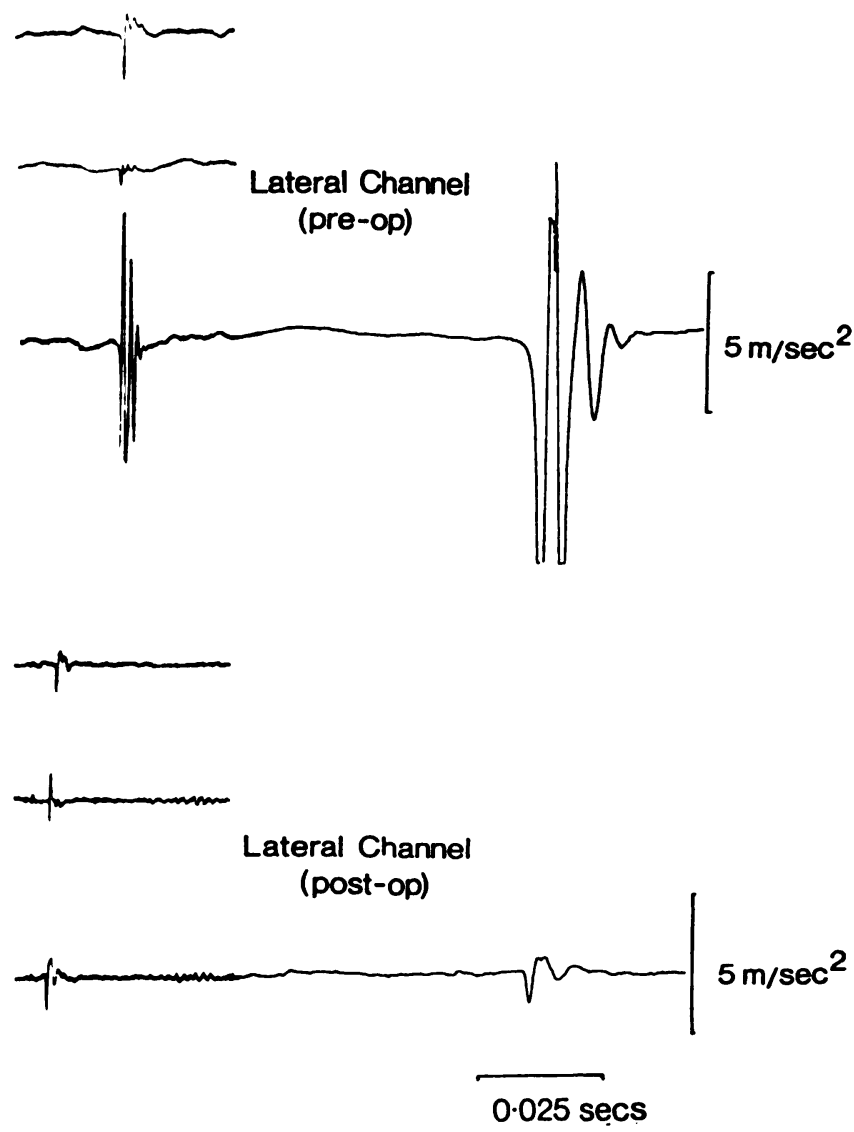

Fig. 7

The effect of surgery on the meniscal signal. The signal recorded postoperatively on the lateral channel is less than one-tenth the amplitude of that observed pre-operatively.
Flexion Extension

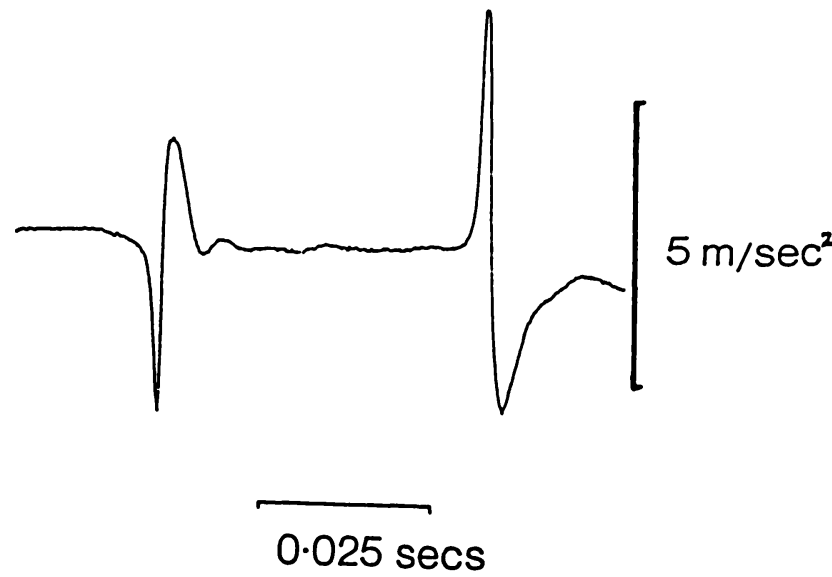

Fig. 8

Signal observed in the case of a medial synovial plica. The signal differs in form between flexion and extension, being initially peak negative in flexion and peak positive in extension.

acts in the manner of a bowstring as it moves across the femoral condyles and the impulse so produced during flexion is opposite in its initial deflection from that produced during extension. Figure 8 is the tracing produced by such a plica on the medial side of the knee, with an initial negative deflection in flexion $\left(\right.$ at $\left.70^{\circ}\right)$ and positive deflection in extension (at $32^{\circ}$ ). The larger amplitude seen in extension may be due to the fact that with the subject seated, extension is the only movement performed actively, flexion being achieved by the force of gravity. The plical signal was found to be abolished by appropriate surgery.

Characteristic signals were also a feature of the degenerate knee. In fast limb cycles, instead of a smooth tracing or an occasional patellar click, the tracing was bizarre and irregular. The frequencies with degeneration were generally higher than those found with meniscal injuries ( 300 to $600 \mathrm{~Hz}$ as opposed to 25 to $320 \mathrm{~Hz}$ ), but further work is required on this aspect of vibration arthrography.

Signal size and timing. The relationship in size between the signal recorded on the affected side and the signals over the patella and the contralateral side appeared to be a function of the angular position in the limb cycle at which the signal occurred. Thus, with Type I buckethandle tears, when the signal tended to occur in midcycle, the patellar signal was intermediate in size between that of the other two (Fig. 9). With the Type III bucket-handle tear, which generally gave a signal when the joint was in a greater degree of flexion, the patellar signal was smaller than that observed over the contralateral side (Fig. 10). Posterior horn tears produced signals close to maximal flexion and, the patellar signal in these cases was often very small (Fig. 11). The full potential of these observations for diagnostic purposes is still being evaluated. 


\section{DISCUSSION}

Vibration arthrography represents an exciting development in the diagnosis of knee disorders. It is noninvasive, the diagnostic accuracy with meniscal injuries was $86 \%$, and characteristic signals were also observed in many other intra-articular derangements. Moreover, significant new knowledge on knee function has been gained from the signals in normal knees (Beverland et al. 1986)

The recording and subsequent analysis of physiological patellofemoral crepitus (PPC) represents an objective measure of the state of the articular cartilage. Our evidence demonstrates that PPC is a manifestation of slip-stick friction (Beverland et al. 1986), and that its quality, amplitude and distribution in the limb cycle accurately reflects cartilage integrity. With cartilage deterioration, the amplitude and incidence of crepitus decreases, and, when radiographic changes become advanced at the patellofemoral joint, the signal is often absent. The potential of this technique in detecting cartilage degeneration prior to radiographic change is clear.

The patellar click, present equally in both normal and symptomatic knees, is not a manifestation of underlying pathology. The routine use of three sensors around the knee localises the signal source and minimises the risk of its misinterpretation as a pathological signal. The source of the patellar click is uncertain. The evidence is that it is different in origin from PPC. An earlier theory that it was due to cavitation is now considered less likely. A more probable cause is a change in patellar orientation as its area of contact moves onto

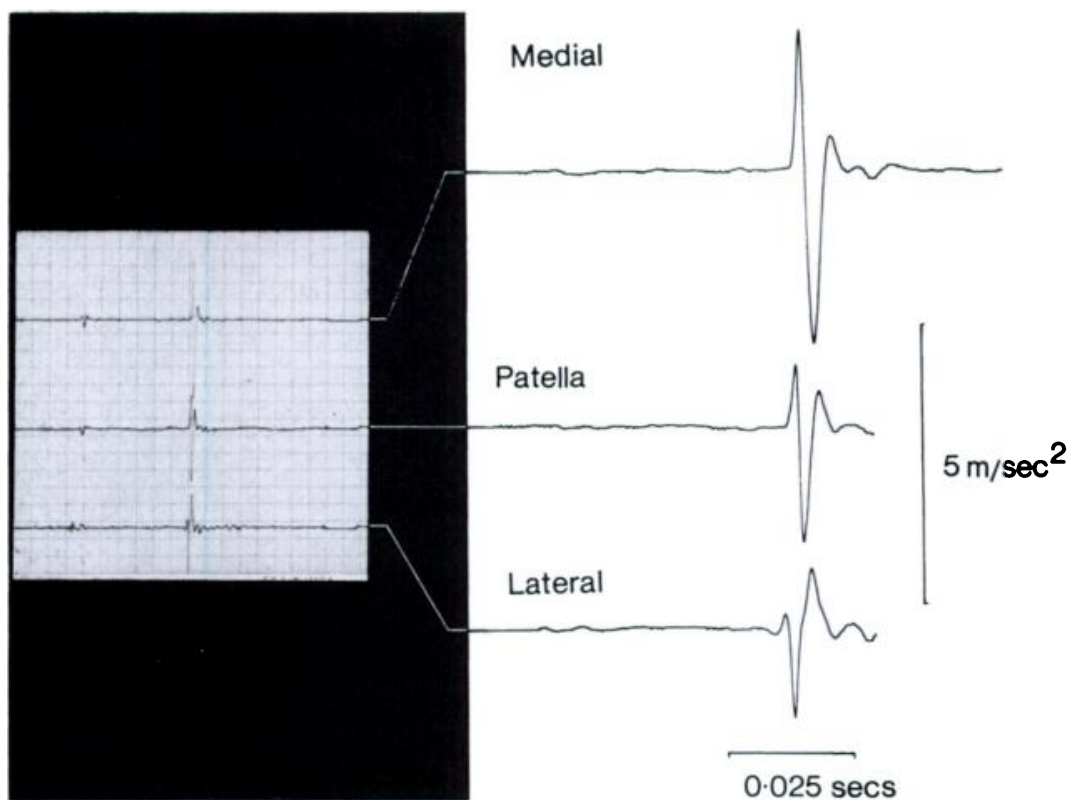

Fig. 9

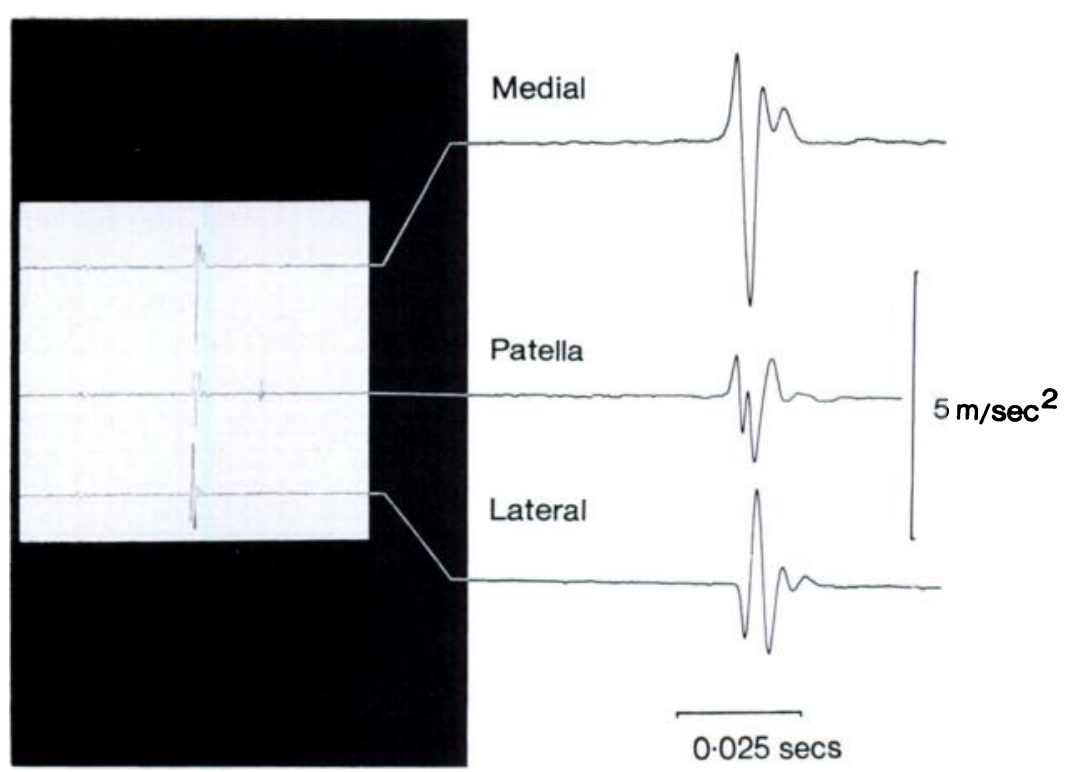

Fig. 10
Figure 9 - Tracing observed in a case of Type I bucket-handle tear of the medial meniscus. The patellar signal is intermediate in size between that of the affected and the contralateral side. Figure $10-$ With a Type III tear, the signal tended to occur with the knee in a greater degree of flexion, and the signal from the patella was smaller than that observed on the contralateral side. 


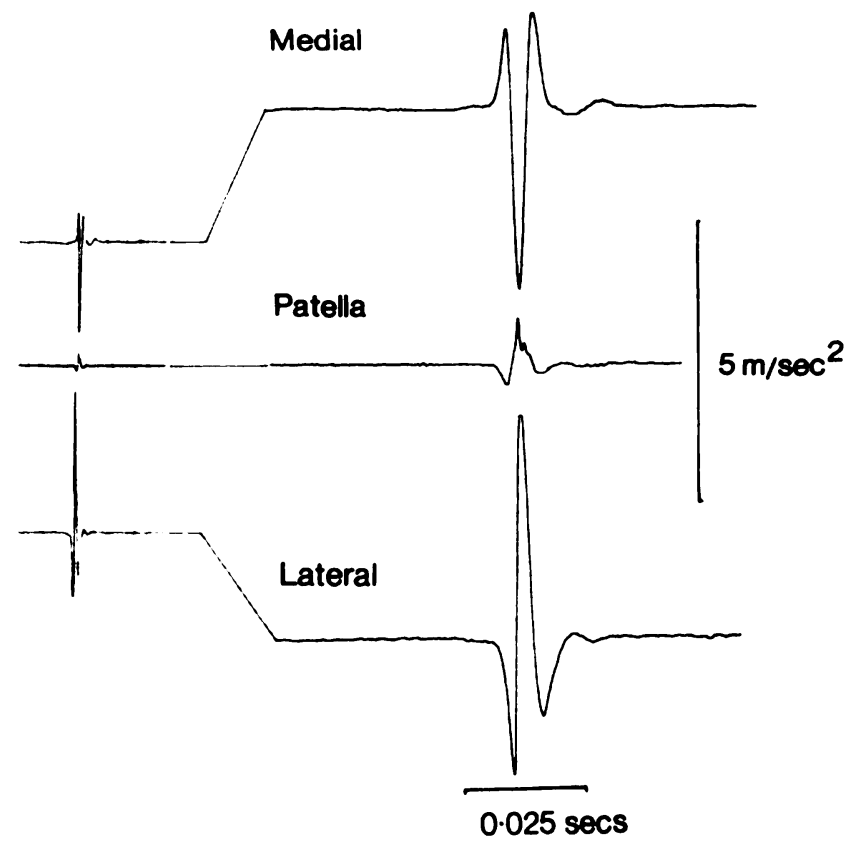

Fig. 11

A true posterior horn tear (in this case of the lateral meniscus) was characterised by a very small patellar displacement. This signal tended to occur with the knee at close to, or greater than, $90^{\circ}$ of flexion.

adjacent facets during extension. The significance of this phenomenon on cartilage wear is unknown and has yet to be fully assessed, but the energies measured from such clicks are significant (Fig. 3).

It is with the diagnosis of meniscal injuries that one major potential of this technique lies. Out of 174 subjects with meniscal lesions proved at operation, 150 produced characteristic signals $(86 \%)$. In all cases the signal was on the correct side of the knee. With the meniscal signal a displacement is generally detected simultaneously on all three channels; it probably results from an alteration in the normal "roll-glide" which occurs during movements of the knee. This concurs with previous work (Frankel, Burstein and Brooks 1971), which ascribed mechanical locking of the knee in meniscal injuries to such an alteration in roll-glide.

The effect of surgery on the meniscal signal was significant. In the example illustrated in Figure 7 operation reduced the energy of the signal by a factor of more than 10. Meniscal signals represent energy imparted to the articular surfaces, as a result of maltracking, by dislocatable lesions of the menisci. As such, the amount of energy detected parallels the potential for further cartilage damage. Meniscectomy is therefore seen to reduce and, in most cases, abolish, this potential for continuing cartilage damage. Moreover, vibration arthrography is seen to be an objective assessment of the efficacy of arthroscopic meniscectomy.
Vibration arthrography has tremendous potential as a diagnostic aid in disorders of the knee. Whilst at present the system is somewhat cumbersome, rapid advances in computer technology will permit its miniaturisation. In addition, the development of "real-time", multi-channel analysis makes the production of a reliable, accurate vibration-based diagnostic kneescreener a distinct possibility.

\section{REFERENCES}

Beverland DE, McCoy GF, Kernohan WG, Mollan RAB. What is patellofemoral crepitus? J Bone Joint Surg [Br] 1986;68-B:496.

Bircher E. Zur Diagnose der Meniscusluxation und des Meniscusabrisses. Zentralbl Chir 1913:40:1852-7.

Blodgett WE. Auscultation of the knee-joint. Boston $M S J$ 1902;146:63-6.

Chu ML, Gradisar IA, Railey MR, et al. An electrico-acoustical technique for the detection of knee joint noise. Med Res Eng $1976 \mathrm{a} ; 12: 18-20$.

Chu ML, Gradisar IA, Railey MR, et al. Detection of knee joint diseases using acoustical pattern recognition technique. $J$ Biomech $1976 \mathrm{~b} ; 9: 111-4$.

Chu ML, Gradisar IA, Zavodney LD. Possible clinical application of a noninvasive monitoring technique of cartilage damage in pathological knee joints. J Clin Eng 1978;3:19-27.

Cowie GH, Mollan RAB, Kernohan WG, Bogues BA. Vibration emission in detecting congenital dislocation of hip. Orthop Rev $1984: 13(1): 30-5$.

Danis L, Szabó E, Török Z. Genophongraphiás görbék osztályozása meniscus séruléseknél. Magy Traumatol Orthop Helyreallito Sebesz 1972;15:202-9.

Erb KH. Über die Möglichkeit der Registrierung von Gelenkgeräuschen. Deutsche Zischr Chir 1933:241:237-45.

Fischer H, Johnson EW. Analysis of sounds from normal and pathologic knee joints. 3rd Int Congr Phys Med 1960;50-7.

Frankel VH, Burstein AH, Brooks DB. Biomechanics of internal derangement of the knee: pathomechanics as determined by analysis of the instant centers of motion. J Bone Joint Surg [Am] 1971;53-A:945-62.

Glasgow M, McClelland CJ, Campbell J, Jackson RW. The synovial plica and its pathological significance in the knee. $J$ Bone Joint Surg [Br] $1981 ; 63-\mathrm{B}: 630$.

Heuter C. Grundriss der chirurgie. 3rd ed. Leipzig: FCW Vogel, 1885

Jackson RW, Abe I. The role of arthroscopy in the management of disorders of the knee: an analysis of 200 consecutive examinations. J Bone Joint Surg [Br] 1972:54-B:310-22.

Kemohan WG, Mollan RAB. Microcomputer analysis of joint vibration. J Microcomp Appl 1982;5:287-96.

Mang W, Birk M, Blümel G. Praktische Anwendbarkeit der Phonoarthrographie in der Kniegelenksdiagnostik. Z Orthop 1980;118:85-90. (Eng. Abstr.)

McCrea JD, McCoy GF, Kemohan WG, McClelland CJ, Mollan RAB. Moderne Tendenzen in der Phonoarthrographie. Z Orthop 1985;123:13-7. (Eng. Abstr.)

Mollan RAB, McCullagh GC, Wilson RI. A critical appraisal of the auscultation of human joints. Clin Orthop 1982;170:231-7.

Oehl R, Bohnenberger J, Heinkelmann W, et al. Zur Technik der Phonoarthrographie. Med Welt 1974;25:1984-9.

Wallace RGH, Mollan RAB, Kemohan WG. Preliminary report on a new technique to aid diagnosis of some disorders found in hands. $J$ Hand Surg $[\mathrm{Br}] 1985 ; 10-\mathrm{B}: 269-72$.

Walters CF. The value of joint auscultation. Lancet 1929;i:920-1. 